\title{
Insurance Coverage for Non-standard Workers: Experiences of Temporary Workers, Freelancers, and Part-time Workers in the USA, 2010-2017
}

\author{
Terceira Ann Berdahl, PhD® and Asako S. Moriya, PhD \\ Agency for Healthcare Research and Quality, 5600 Fishers Lane, Rockville, MD, USA.
}

\begin{abstract}
OBJECTIVE: To estimate insurance disparities across non-standard employment categories and to determine how coverage disparities shifted following health reform in 2014.

METHODS: We analyzed nationally representative data on working-age adults from the Medical Expenditure Panel Survey (MEPS) (2010-2012 and 2015-2017, N=79, 182) to estimate insurance rates across three groups of nonstandard workers (full-time temporary workers, freelancers, and part-time workers) compared to standard workers.
\end{abstract}

RESULTS: Uninsurance decreased after health reform for all groups of non-standard workers, ranging from a 10.0to 14.3 -percentage point decline $(p<0.001)$. Yet, uninsurance rates remained high for freelancers (30.8\%), full-time temporary workers (25.1\%), and parttime workers (17.9\%) relative to standard workers (11.9\%) in 2015-2017 ( $p<0.001)$. Residence in a Medicaid expansion state was associated with lower uninsurance rates for all categories of workers.

CONCLUSIONS: Workers in non-standard jobs continue to face challenges obtaining health insurance coverage. Our findings highlight the continued high risk of uninsurance for full-time temporary workers and freelancers.

KEY WORDS: health insurance; non-standard workers; health policy; poverty.

J Gen Intern Med 36(7):1997-2003

DOI: $10.1007 / \mathrm{s} 11606-021-06700-0$

(C) This is a U.S. government work and not under copyright protection in the U.S.; foreign copyright protection may apply 2021

\section{INTRODUCTION}

Prompted by the growing vulnerability of workers to widespread organizational restructuring, job loss, and downward mobility, researchers are increasingly concerned about the health implications of the transformation of work in an increasingly flexible "gig" economy. ${ }^{1}$ One such implication is the lack of access to health insurance, especially for workers in non-standard jobs. Prior research on the US labor market found that non-standard work has been increasing in the

Received June 22, 2020

Accepted March 7, 2021

Published online March 26, 2021
USA for several decades, pre-dating the "gig" economy, the Great Recession, and the COVID-19 pandemic recession, a recession which has dramatically increased unemployment levels in $2020 .^{2-5}$ Beyond insurance, non-standard work exposes workers to poor working conditions ${ }^{6}$ that potentially increase healthcare needs. ${ }^{1}$

\section{Background}

Non-standard jobs do not typically provide predictable, fulltime employment with a "gold" standard set of benefits, and hence non-standard workers are less likely to have health insurance, compared to other workers. ${ }^{3,}{ }^{4,}{ }^{6-8}$ Prior studies have documented higher uninsurance rates for categories of non-standard workers defined by work hours (part-time workers) and self-employment. ${ }^{9,10}$ Self-employed freelancers and gig economy workers also face challenges to obtaining health insurance coverage since they do not have access to employer-sponsored insurance (ESI) through their jobs. Finally, most employers do not offer fringe benefits to temporary workers. While the flexibility of non-standard jobs may be appealing to some workers, many hold non-standard jobs involuntarily and some workers rely on a non-standard job as the only potential source of ESI. ${ }^{8,11,12}$

Health insurance disparities for non-standard workers have many implications for clinicians. First, many non-standard workers face greater job hazards in the workplace. ${ }^{1,}{ }^{6}$ For example, temporary workers often have less training and higher workplace injury rates in some industries. ${ }^{6}$ Second, gaps in insurance coverage are more common for these workers, which has implications on healthcare utilization and management of chronic disease. ${ }^{13}$ Gaps in coverage can lead to missed preventive medicine opportunities, including cancer screenings. ${ }^{14}$ While employment status is not typically asked about by physicians or insurance companies, nor is it commonly included in electronic health records, the implications for health status make it likely to be a useful consideration for physicians of all patients, especially those who are uninsured or underinsured. ${ }^{15}$

Health reforms created through the Affordable Care Act (ACA) extended insurance coverage for non-standard workers mainly by (1) providing public coverage options to lowincome workers who reside in states that expanded Medicaid, and by (2) offering subsidized coverage to workers with low- 
to-moderate family income through Marketplace coverage. Even with these reforms, non-standard workers may still encounter challenges obtaining coverage because of unpredictable incomes and uncertainty regarding Medicaid eligibility status. Also, Marketplace coverage may not be an affordable option to non-standard workers, depending on the workers' age, income, and rating area. Finally, most very low-income workers in non-expansion states are ineligible for either Medicaid or Marketplace subsidies.

\section{Current Study Contributions}

Our study explores coverage disparities for three groups of workers: freelancers, full-time temporary, and part-time. While they are all vulnerable to uninsurance, their insurance options and demand may differ depending on the nature of their jobs and also on their demographic and socioeconomic characteristics. For example, many part-time workers have access to insurance coverage through a spouse, while freelancers do not have any access to employer benefits. Prior research found that the ACA was associated with lower uninsurance rates for some categories of non-standard workers. ${ }^{10,16}$ However, few studies have evaluated insurance coverage status using complex definitions of employment and insurance to evaluate non-standard workers and we know of no studies that provide detailed estimates of policy-relevant insurance categories for full-time temporary workers and freelancers by residence in a Medicaid expansion state. In the current study, we addressed these gaps in the literature by providing an evaluation of how expanded health insurance coverage impacted more refined categories of non-standard workers.

\section{METHODS}

\section{Data}

We used data from the Medical Expenditure Panel Survey (MEPS) Household Component, a nationally representative survey of the US non-institutionalized civilian population. Our study uses pooled annual data for two time periods (2010 2012 and 2015-2017) allowing for comparisons before and after 2014. To account for lagged insurance enrollment, the post-ACA time period excludes the year $2014 .{ }^{10}$ All estimates were weighted and adjusted for the complex survey design of MEPS using the Taylor linearization complex survey design commands in Stata 15.0. Our sample included 79,182 workers representing the two time periods. Our study sample included working-age adults 19-64 years old and our analysis focused on individuals' current main jobs.

\section{Variables}

Our outcome variables of interest were uninsurance at the time of the interview, as well as employer-sponsored insurance (ESI, as either the policyholder or a dependent), other private coverage (including coverage purchased in the non-group market or through the ACA Marketplaces), Medicaid, and other public insurance. Control variables used in regression models included gender, race/ethnicity, age, marital status, education, region, and self-rated health. Standard jobs are those with stable and fixed schedules, full-time work hours, health insurance and other benefits, and some degree of permanence (i.e., not temporary). ${ }^{3}$ Non-standard jobs can be defined as those lacking these characteristics. Although there is no universal definition of non-standard work, there are some common measures used in prior research and MEPS includes them. ${ }^{1,3,4}$ For example, MEPS measures temporary work status, seasonal employment, and work hours for current main jobs. MEPS also includes measures of selfemployment and incorporation status, as well as establishment size, allowing us to capture freelancers. Our three categories of non-standard workers were defined hierarchically in the following order: (1) freelancers are unincorporated self-employed workers with no employees (this category includes independent contractors); (2) full-time temporary workers are those who work full time, but whose main jobs are temporary and/or seasonal; and (3) part-time workers are those who work fewer than $30 \mathrm{~h}$ per week on average. Employment variables in MEPS are more detailed than other health surveys and they allow us to define our categories of non-standard workers in a way comparable to the Current Population Survey Contingent Worker Survey (CPS-CWS). ${ }^{19}$ We categorized workers with family incomes of $400 \%$ of the federal poverty level (FPL) or less as "lower-income," and workers with family incomes of more than $400 \%$ FPL as "higher-income" in our subgroup analysis. We used the 400\% FPL threshold partly because those with modified adjusted gross income (MAGI) between 0 and $400 \%$ of FPL became eligible for the ACA premium subsidies starting from 2014. Our lower-income sample included those who gained Medicaid eligibility through the ACA since its MAGI eligibility threshold was set as $138 \%$. We coded the Medicaid expansion state variable using state of residence information available in restricted-use MEPS file (see Appendix Table 9).

\section{Analytic Approach}

Our analysis began with descriptive estimates of all insurance outcomes for each of the four employment categories in the pre-ACA time period (2010-2012) and the postACA time period (2015-2017). Next, we obtained regression-adjusted changes for each insurance outcome, controlling for demographic and socioeconomic characteristics that may have changed over time (see Appendix for details). We included the variables mentioned in the "Data" section in our models. After evaluating the overall change in insurance status, we focused our analysis on 
remaining insurance disparities in the post-ACA time period. We focused on income and residence in a Medicaid expansion state to better understand the role of nonstandard employment status, especially for lower-income workers.

\section{RESULTS}

The three groups of non-standard workers comprised a total of $23.1 \%$ of all US workers (annualized average weighted estimates represent 32.4 million workers). Of the three groups, $5.2 \%$ were freelancers, $5.2 \%$ were full-time temporary workers, and $12.7 \%$ were part-time workers. Freelancers were older and full-time temporary workers and part-time workers were younger than standard workers on average (Appendix Table 1). Part-time workers were more likely to be women compared to standard workers. As for racial compositions, freelancers were less likely to be non-Hispanic black and full-time temporary workers were more likely to be Hispanic compared to standard workers. Both full-time temporary workers and part-time workers were less likely to be married than standard workers, possibly reflecting their age differences. Workers in all three categories of non-standard workers tended to have lower family income compared to standard workers, and average family income was highest for freelancers and lowest for part-time workers among nonstandard workers.
In 2010-2012, non-standard workers had higher uninsurance rates compared to standard workers (see Fig. 1). Freelancers had higher uninsurance rates $(45.2 \%)$ compared to full-time temporary workers (34.8\%) and part-time workers (29.7\%). A major source of insurance was ESI coverage from the worker's own job for full-time temporary workers and standard workers (36.6\% and $63.9 \%$, respectively) and ESI coverage as a dependent for freelancers and part-time workers (35.4\% and $35.6 \%)$. Other private coverage was held by $12.4 \%$ and $11.6 \%$ of freelancers and part-time workers. Across non-standard worker categories, 4.4 to $8.7 \%$ were covered by Medicaid prior to 2014.

All three groups of non-standard workers experienced substantial declines in uninsurance rates in 2015-2017, ranging from a 10.0-percentage point decline (full-time temporary workers) to a 14.3-percentage point decline (freelancers) (Fig. 2). The sources of coverage gains differed by the types of non-standard work: freelancers primarily gained other private coverage, mainly through Marketplace, (an 11.0-percentage point increase) and part-time workers benefited from Medicaid expansion (a 9.9-percentage point increase), while many full-time temporary workers obtained coverage from both sources (2.2- and 3.4-percentage point increases in other private and Medicaid coverage, respectively).

Despite large decreases, uninsurance rates remained higher for all three types of non-standard workers than for standard workers (11.9\%) in 2015-2017 (Fig. 1). The uninsurance rate was higher for freelancers $(30.8 \%)$ and full-time temporary

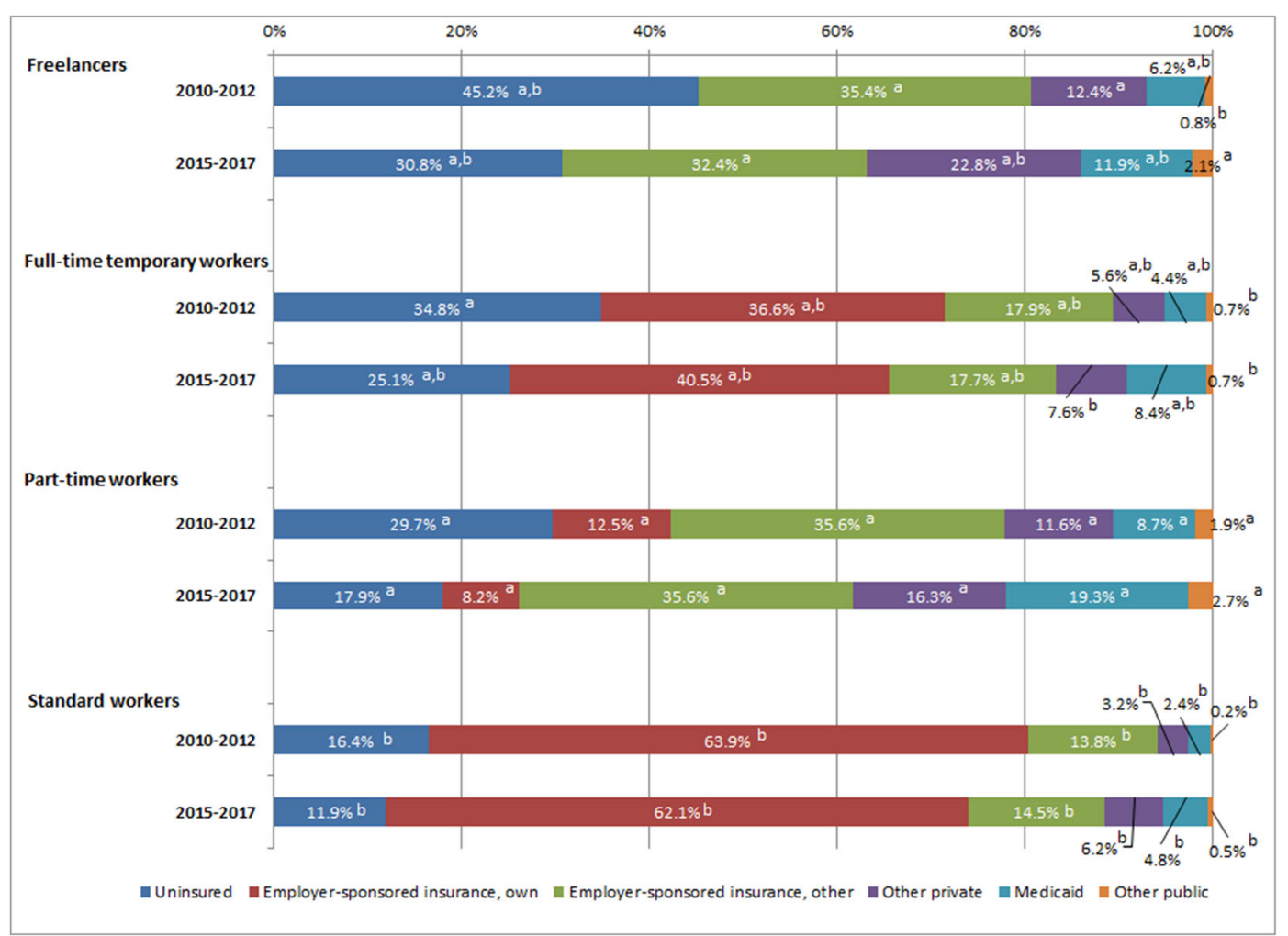

Figure 1 Insurance status among non-elderly workers by work arrangement category in 2010-2012 and 2015-2017. Note. ${ }^{\text {a Statistically }}$ significant difference at the $p<.05$ level compared to standard workers. ${ }^{b}$ Statistical difference at the $p<.05$ level compared to part-time workers. 
workers $(25.1 \%)$ relative to part-time workers (17.9\%). Many of the non-standard workers - one in three freelancers and part-time workers and nearly one in five full-time temporary workers - still relied on ESI coverage obtained as a dependent. The main source of coverage for full-time temporary workers was still ESI from their own job (40.5\%). Other private coverage (mainly Marketplace) and Medicaid were also important sources of coverage for non-standard workers after healthcare reforms. Almost one in four freelancers had other private coverage, followed by part-time workers $(16.3 \%)$ and fulltime temporary workers $(7.6 \%)$. Medicaid coverage rates ranged from $11.9 \%$ (full-time temporary workers) to $19.3 \%$ (part-time workers). On the other hand, most standard workers still obtained coverage through their own employers (62.1\%). Standard workers were less likely to have Medicaid and other private coverage compared to non-standard workers both before and after the healthcare reforms.

We now turn to insurance disparities by household income for the post-ACA years in our study (2015-2017). 40.1\% of lower-income freelancers and $37.7 \%$ of lower-income fulltime temporary workers were still uninsured in 2015-2017 (Fig. 3). Although higher-income non-standard workers were less likely to be uninsured compared to their lower-income counterparts, 20.8\% of higher-income freelancers were uninsured in 2015-2017. Regardless of work arrangement categories, higher-income workers were more likely to be covered by ESI (both as a policy holder and as a dependent) and less likely to have had Medicaid coverage than their lower-income counterparts. Among lower-income workers, standard workers had the lowest uninsurance rates $(19.8 \%)$ and the highest rates with own ESI (52.9\%).

Our final figure (Fig. 4) highlights insurance disparities by state Medicaid expansion status for lower-income workers. For each lower-income worker group, those living in states that expanded Medicaid had lower rates of uninsurance and higher rates of Medicaid coverage, compared to their counterparts living in non-expansion states. Nearly half of lowerincome freelancers $(48.9 \%)$ and full-time temporary workers (45.0\%) had no insurance if they resided in a non-expansion state, while about one-third of their counterparts in expansion states were uninsured. The rate of those covered by Medicaid was $38.4,26.6$, and $22.8 \%$ among lower-income part-time workers, freelancers, and full-time temporary workers in expansion states while the rates were $12.9,7.2$, and $4.5 \%$ in nonexpansion states, respectively.

\section{DISCUSSION}

Hundreds of studies have documented the impact of the ACA health reform on insurance coverage, ${ }^{20}$ although very few focused on the subsets of non-standard workers included in the present study. A recent paper by Su et al. (2019) is one notable exception. ${ }^{16} \mathrm{Su}$ et al. (2019) analyzed 2 years of

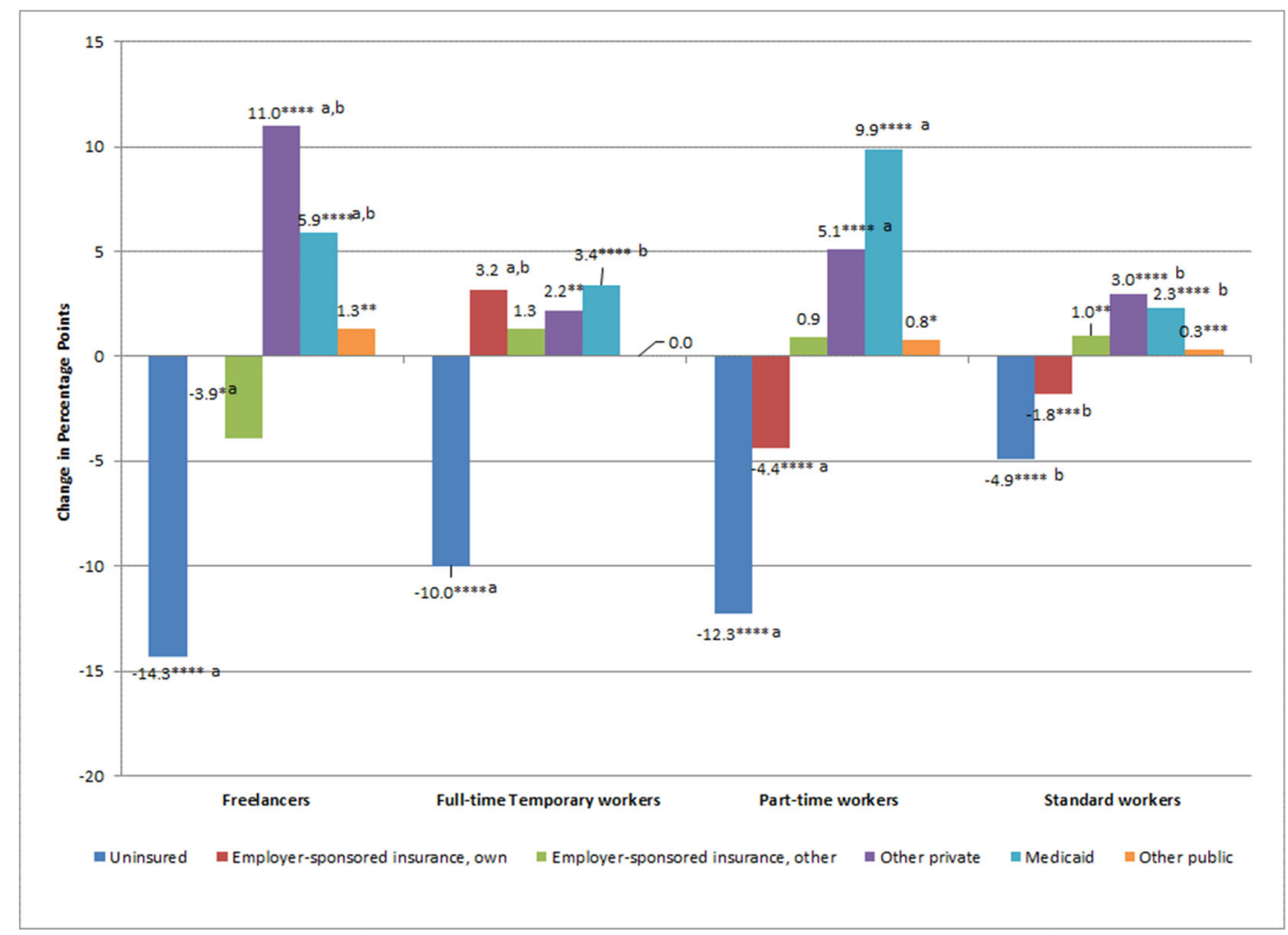

Figure 2 Regression-adjusted changes in insurance status between 2010-2012 and 2015-2017 among non-elderly workers by work arrangement category. Note. $* * * *, * * *, * *, *$ : statistically significant change over time within worker category at the $p<.001, p<.01, p<.05$, and $p<.10$ level.

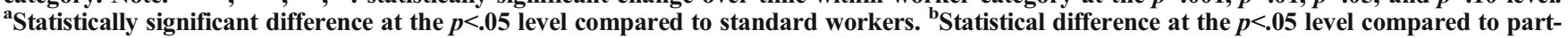
time workers. 


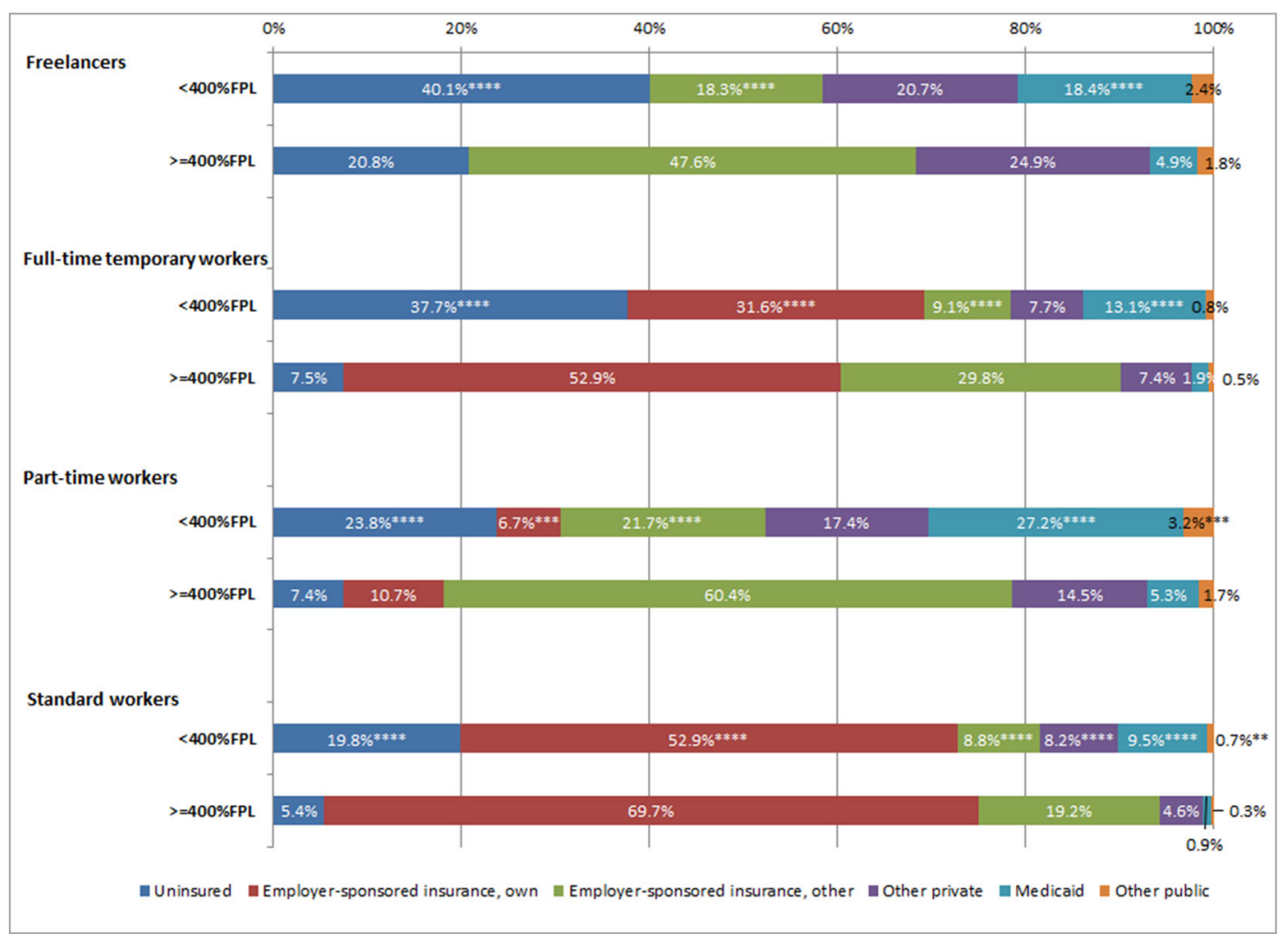

Figure 3 Insurance status among non-elderly workers by work arrangement category and household income in 2015-2017. Note. FPL, federal poverty level. $* * * *, * * *, * *$, and $*$ indicate statistically significant difference at the $p<.001, p<.01, p<.05$, and $p<.10$ level between the two income categories.

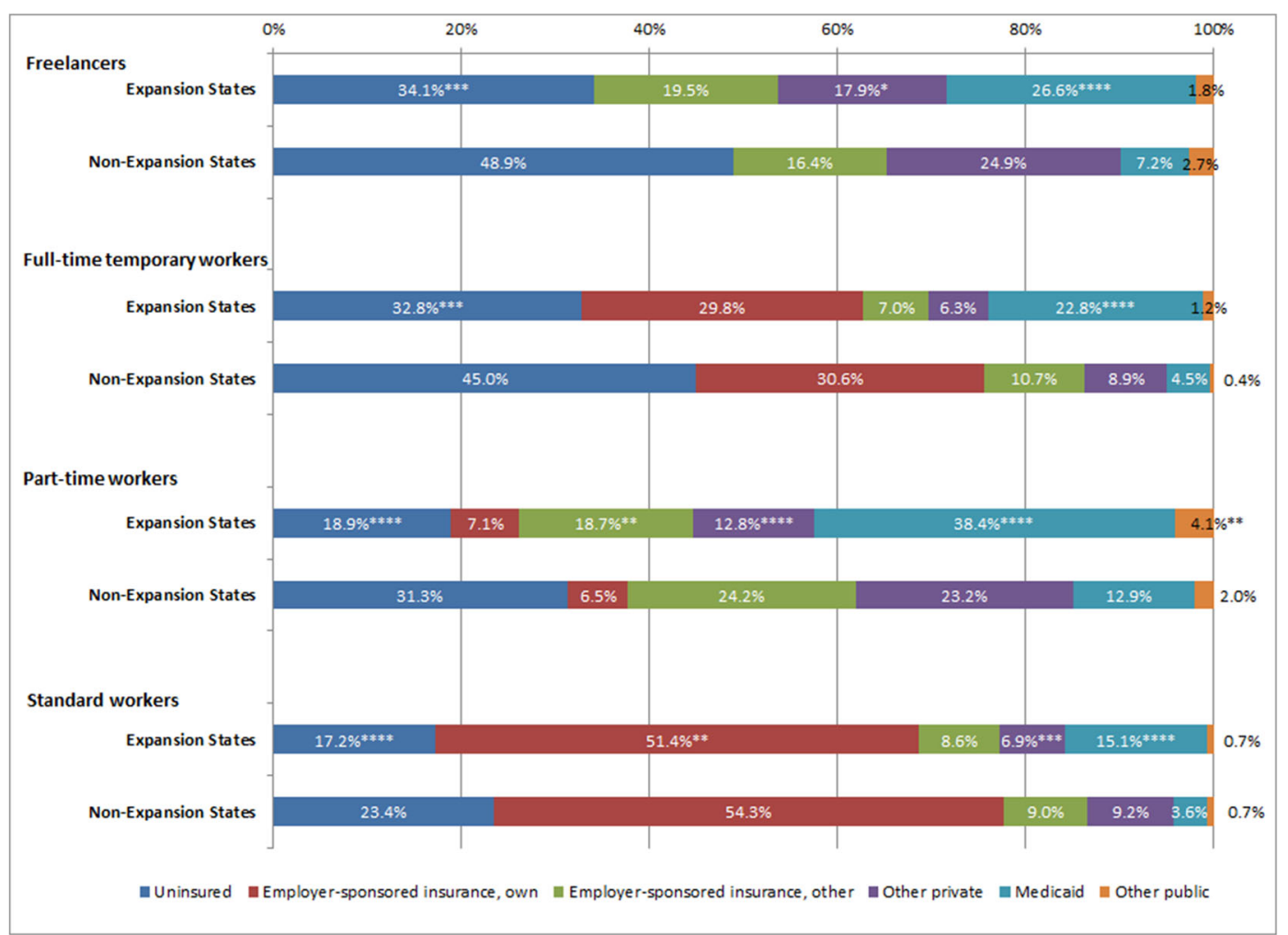

Figure 4 Insurance status among non-elderly workers by work arrangement category and state Medicaid expansion status for workers in lower income $(<400 \%$ FPL) in $2015-2017$. Note. FPL, federal poverty level. $* * * *$, $* * * * *$, and $*$ indicate statistically significant difference at the $p<.001, p<.01, p<.05$, and $p<.10$ level between expansion and non-expansion states (see Appendix for the list of expansion and non-expansion states). 
survey data from the NHIS and explored uninsurance differences for non-standard workers; however, their study design did not include the same categories of non-standard work or insurance coverage compared to the current study, nor did they compare workers across expansion states. ${ }^{16}$ The present study builds on this work and the large volume of studies finding changes in insurance status for a wide range of workers following the ACA. ${ }^{17}, 18,20$

The current study illustrates the importance of conceptualizing different non-standard worker groups and their pathways to accessing health insurance. The analyses comparing postand pre-2014 showed different pathways to coverage and uninsurance levels among freelancers, full-time temporary workers, and part-time workers. Our findings are novel because no prior studies have used nationally representative data to examine freelancers (self-employed non-employer firms) and full-time temporary workers, specifically. These two groups are critical to study because they represent nonstandard employment categories at risk of higher levels of uninsurance. Our study further examined the avenues through which non-standard workers obtained insurance coverage following health reform. Many workers relied on ESI coverage obtained as a dependent. Lower rates of own-job ESI coverage for freelancers were likely the cause of high uninsurance rates for this group (including higher-income freelancers). The main sources of non-ESI coverage gains were other private (mainly Marketplace) for freelancers, Medicaid coverage for part-time workers, and a more equal mix of other private and Medicaid coverage for full-time temporary workers, likely reflecting the income differences across these categories. The importance of Marketplace coverage for freelancers has significance as "gig" economy jobs are captured in this group. Our findings highlight policy-relevant groups of workers who are impacted by ACA-related health reform.

The relationship between employment status and access to health insurance is complex. The dynamics of non-standard employment and insurance disparities are highly relevant to the unemployed, as the most common pathway back to the labor market after being unemployed is through a nonstandard job. For example, recent research found that nonstandard employment is more common for workers who enter the labor market after a spell of unemployment. ${ }^{21}$ The ease of entry to non-standard employment means that the way that workers enter and exit jobs has great relevance for household income volatility and access to any type of insurance. Furthermore, non-standard workers are at an increased risk of job loss. Involuntary unemployment and job losses stemming from the pandemic are large and heavily impact part-time workers and self-employed workers ${ }^{2}$ as well as industries including food service and construction, where non-standard work arrangements are common.

Many non-standard workers cannot predict their work hours, making it difficult for them to know whether their income qualifies them for subsidies or Medicaid coverage or plan for paying medical bills. ${ }^{22}$ With Medicaid work requirements gaining popularity, our findings highlight another pressing problem: many workers who have non-standard jobs have gained coverage through Medicaid expansion, but they could face a higher risk of losing the coverage due to the fluctuation and unpredictability of their work hours once work requirement is implemented. The overall insecurity of jobs in the US labor market and increasingly complex patterns of informal work (or formal work in the gig economy) create challenges for the continuity of insurance and also for enrollment in public insurance programs, such as Medicaid.

Although our paper controlled for health status and focused on insurance, our findings can inspire physicians and medical institutions to use social determinants of health (SDOH) codes to capture unemployment and also employment in nonstandard jobs. Our findings highlight the importance of employment status as a $\mathrm{SDOH}$ and identify another reason why recent policy and research efforts to better capture and address social determinants are important. ${ }^{15}$ If physicians use the new social determinants of health codes ICD-10 " $\mathrm{z}$ codes," these types of risk factors for both poor health and for less than unstable insurance coverage could lead to better tracking and management of health conditions.

\section{Limitations}

Our study had the following limitations. First, the MEPS did not include questions enabling identification of smaller subgroups of non-standard workers, such as on-call workers, workers provided by contract firms, and those who participated in the digital or sharing economy. Although these work arrangements could not be uniquely identified in MEPS, they comprise a small share of non-standard jobs overall and many of them are included in our non-standard employment category (e.g., temporary or part-time workers). ${ }^{10,}{ }^{19}$ Second, self-employed independent contractors who work for the same firms for a long time often report in surveys that they are employed by the firms (creating a misclassification of self-employment status). Solving this issue of misclassification is an important future step for the MEPS and other household surveys. ${ }^{23}$ Lastly, post-2014 changes may not be solely attributable to the effects of the ACA, and could include the effects of concurrent trends and potential changes in the composition of non-standard workers. Although the trend in non-standard work has not shown dramatic shifts in our study period, we found some evidence of demographic shifts (see Appendix). Also, our post-2014 comparison of expansion vs. non-expansion states may capture additional underlying differences between the two sets of the states. However, there is abundant evidence that the 2014 Medicaid expansions increased insurance coverage overall and among many subgroups of population, and there is no other intervention as large and impactful as the ACA insurance expansion that occurred around 2014.

\section{Conclusion}

Whether or not public health policy can buffer workers from the increasingly insecure economy remains an important 
question. ${ }^{24}$ Our study highlights the vulnerability of freelancers and full-time temporary workers, who are most at risk of being uninsured, even at higher incomes. Non-standard workers with limited economic resources still face high uninsurance rates even after the recent substantial coverage expansions. Future research should consider more complex definitions of employment status to address the increased uninsurance risk faced by workers in various types of nonstandard employment, a category of work that will only continue to rise in the aftermath of COVID-19 layoffs and losses. $^{25}$

Acknowledgements: The findings and conclusions in this paper are solely those of the authors and do not necessarily represent the views of the Department of Health and Human Services or the Agency for Healthcare Research and Quality. The authors thank Joel Cohen, Patricia Keenan, G. Edward Miller, Thomas M. Selden, the JGIM editorial staff and anonymous peer reviewers for helpful feedback on the manuscript.

Corresponding Author: Terceira Ann Berdahl, $\mathrm{PhD}$; Agency for Healthcare Research and Quality, 5600 Fishers Lane, Rockville, MD 20852, USA (e-mail: Terceira.berdahl@ahrq.hhs.gov).

Supplementary Information The online version contains supplementary material available at https://doi.org/10.1007/ s11606-021-06700-0.

\section{Declarations:}

Conflict of Interest: The authors declare that they do not have a conflict of interest.

\section{REFERENCES}

1. Benach J, Benavides FG, Platt S, Diez-Roux A, Muntaner C. "The health-damaging potential of new types of flexible employment: a challenge for public health researchers." American Journal of Public Health. 2000;90(8), 1316.

2. U.S. Bureau of Labor Statistics. "Supplemental data measuring the effects of the coronavirus (COVID-19) pandemic on the labor market." October 2, 2020.

3. Kalleberg AL, Reskin BF, Hudson K. "Bad jobs in America: Standard and nonstandard employment relations and job quality in the United States." Am Sociol Rev. 2000;256-278.

4. Katz LF, Krueger AB. "The Rise and Nature of Alternative Work Arrangements in the United States, 1995-2015.” ILR Review. 2019;72(2) 382-416.

5. Government Accountability Office (GAO) 2015. "Contingent Workforce: Size, Characteristics, Earnings, and Benefits" GAO-15-168R 2015.
6. Howard J. "Nonstandard work arrangements and worker health and safety." American Journal of Industrial Medicine. 2017:60(1), 1-10.

7. Kalleberg AL. Good Jobs, Bad Jobs. New York, NY: Russell Sage Foundation; 2011.

8. Glauber RK. "Involuntary Part-Time Employment: A Slow and Uneven Economic Recovery." The Carsey School of Public Policy at the Scholars' Repository. 2017;300.

9. Fronstin P. "Trends in Health Coverage for Part-Time Workers." Employee Benefit Research Institute, May 34 No. 5; 2013.

10. Berdahl TA, Moriya AS. "Difference In Uninsurance Rates Between FullAnd Part-Time Workers Declined In 2014." Health Affairs. 2018;37(10): 1669-1672.

11. Shafer HL. "Part-time workers: some key differences between primary and secondary earners." Monthly Labor Review. 2009;1:3-15.

12. Medical Expenditure Panel Survey Insurance Component 2018 Chartbook. Rockville, MD: Agency for Healthcare Research and Quality; September 2019. AHRQ Publication No. 19-0077. https://meps.ahrq. gov/mepsweb/data_files/publications/cb23/cb23.shtml.

13. Simon K, Soni A, Cawley J. The impact of health insurance on preventive care and health behaviors: evidence from the first two years of the ACA Medicaid expansions. Journal of Policy Analysis and Management. 2017;36(2), 390-417.

14. Zhao G, Okoro CA, Li J, Town M. "Health insurance status and clinical cancer screenings among US adults." American journal of preventive medicine. 2018;54(1), e11-e19.

15. Gottlieb L, et al. "Integrating social and medical data to improve population health: opportunities and barriers." Health Affairs. 2016;35.11: 2116-2123.

16. Su CP, Asfaw A, Tamers SL, Luckhaupt SE. Health Insurance Coverage Among US Workers: Differences by Work Arrangements in 2010 and 2015. American journal of preventive medicine. 2019;56(5), 673-679.

17. Frean M, Gruber J, Sommers BD. Premium subsidies, the mandate, and Medicaid expansion: Coverage effects of the Affordable Care Act. J Health Econ. 2017;53:72-86.

18. Kaye, H. S. 2019. "Disability-related disparities in access to health care before (2008-2010) and after (2015-2017) the Affordable Care Act." American Journal of Public Health, 109(7): 1015-1021.

19. Current Population Survey, Bureau of Labor Statistics. News release: contingent worker supplement, 2017. 2018. Downloaded January $9^{\text {th }}$, 2019. ttps://www.bls.gov/news.release/pdf/conemp.pdf.

20. Antonisse L, Garfield R, R Rudowitz, Artiga S. "The Effects of Medicaid Expansion under the ACA: Updated Findings from a Literature Review." Kaiser Family Foundation, March Issue Brief, Washington, DC; 2018.

21. Katz LF, KruegerAB. "The role of unemployment in the rise in alternative work arrangements.” American Economic Review.2017;107 (5): 388-92.

22. McGrath DM, Keister LA. The effect of temporary employment on asset accumulation processes. Work and Occupations. 2008;35(2):196-222.

23. Jackson E, Looney A, Ramnath S. 2017. The rise of alternative work arrangements: evidence and implications for tax filing and benefit coverage. Office of Tax Analysis Working Paper. 114.

24. Kalleberg AL, Vallas SP. "Probing precarious work: theory, research, and politics." Research in the Sociology of Work, 2018; 31: 1-30.

25. Agarwal SD, Sommers BD. Insurance Coverage after Job Loss-The Importance of the ACA during the Covid-Associated Recession. New England Journal of Medicine. 2020.

Publisher's Note: Springer Nature remains neutral with regard to jurisdictional claims in published maps and institutional affiliations. 